\title{
LA POLITICA DE NOMBRAMIENTO DE CORREGIDORES EN EL SIGLO XV: ENTRE LA ESTRATEGIA REGIA Y LA OPOSICION CIUDADANA
}

Yolanda Guerrero Navarrrete

Universidad Autónoma de Madrid

El proceso y evolución que conduce a la génesis del sistema de poder que la historia conoce con el nombre de Estado Moderno ha atraido poderosamente la atención de los historiadores en los últimos años ${ }^{(1)}$.A estas recientes aportaciones debemos su articulación en base a tres procesos paralelos: el que en el plano de la maduración ideológica conduce a los primeros enunciados teóricos, esbozos del futuro poder absoluto; el que en el nivel de la administración, y mediante una sistemática labor de centralización, convierte a la monarquía en el régimen más efectivo, provocando la aparición de una incipiente burocracia; $y$, por último, el que permite la extensión de la jurisdicción regia a todo el territorio mediante la eliminación, absorción o neutralización de los resortes de poder existentes en el reino y hasta ese momento ajenos al directo control de la Corona.

Por el momento nos interesa especialmente este último. La estrategia de los monarcas en este plano debía estar orientada a conseguir, no sólo la difícil "domesticación" de la nobleza, sino también la no menos necesaria transformación de los regímenes municipales, con el fin de posibilitar, primero, su neutralización como resortes de poder ajenos a la Corona y, finalmente, su ulterior utilización como cédulas administrativas al servicio del estado centralizado. Es un hecho, pues, claramente demostrado que las relaciones Corona-municipios en los últimos años de la Edad Media poseen un interés especial que, paradójicamente, no se haya en absoluto apoyado por un ni siquiera suficiente bagaje bibliográfico ${ }^{(2)}$.

En este sentido, hace ya algunos años que vengo interesándome en estas relaciones corona-municipios, asi como en la proyección que las mismas tuvieron en las estructuras urbanas, primero, y en el proceso político castellano, después. Fruto de estos trabajos, todavía diseminados ${ }^{(3)}$, es, por el momento, la reafirmación de ciertas convicciones que, aun cuando 
debidamente expuestas en las aportaciones ya mencionadas, conviene resumir brevemente, en tanto en cuanto van a constituirse en el punto de partida del presente trabajo.

A mediados del siglo XIII los concejos castellanos han culminado una evolución histórica que, al socaire de los fueros y privilegios concedidos por los diferentes monarcas, ha cristalizado definitivamente en un sistema de poder único, indisolublemente unido al marco y a la lógica urbana, y que en definitiva no es sino el resultado final de ese necesario proceso, a la vez de afirmación y defensa, que permite a las ciudades singularizarse frente al resto de los poderes feudales castellanos del momento. Producto de ello es que, ya en la centuria del trescientos, las ciudades participan activa y decisivamente en el juego político castellano. Primero, porque controlan la casi totalidad de la fiscalidad regia de la época; segundo, porque de sus milicias depende en gran medida el éxito y la efectividad de muchas de las empresas del monarca; tercero, porque a través de sus órganos solidarios Cortes y Hermandades- se deja oir significativamente su voz en los acontecimientos políticos del reino.

Sin embargo, es precisamente a partir de esta época -mediados del siglo XIII-, cuando va a notarse el inicio de un radical y definitivo cambio de signo. Alejada definitivamente la frontera, los reyes castellanos, ya no tan necesitados de apoyo militar, ven con mucho recelo la independencia de los concejos. Se iniciará entonces una política tendente a transformar los regímenes municipales con el fin de anular su carácter de resortes de poder independientes y convertirlos en cédulas al servicio de la Corona. Este proceso, que en Castilla puede ser considerado como una de las vias principales de consolidación de la primera fórmula de Estado Moderno, será la última razón subyacente a la promulgación del Fuero Real por Alfonso X, a la consolidación de los regimientos por Alfonso XI y a la lenta y paciente política de mediatización desarrollada por todos y cada uno de los Trastámara.

A grandes rasgos, es factible reconstruir las líneas fundamentales de la estrategia desarrollada por los diferentes monarcas en este proceso. Uno de sus primeros éxitos debe contabilizarse en el marco de la fiscalidad. Poco a poco, los reyes castellanos lograron ir consolidando un sistema impositivo fruto en gran medida de la cesión con carácter ordinario de rentas anteriormente de índole estríctamente urbana. El ejemplo más característico al respecto es la alcabala. Cedida definitivamente a la Corona a fines del siglo XIV, logró convertirse en el símbolo por excelencia del moderno sistema impositivo de los Trastámara, al menos hasta que la pérdida de los impuestos ordinarios en beneficio de la nobleza obligara, ya en tiempos de los Reyes Católicos, a fundamentar la hacienda regia sobre los impuestos extraordinarios ${ }^{(4)}$. Sin embargo el éxito más definitivo en este campo se logró con la generalización del régimen de arrendamientos como método único para la recaudación de impuestos. Con ello se liberó definitivamente a la Corona de la dependencia fiscal mantenida hasta ese momento con respecto a los concejos al dejar a estos definitivamente al margen de la 
gestión y control de los impuestos. Desde finales del siglo XIV los concejos castellanos se limitan a pagar al monarca las cantidades que éste periódicamente demanda. Antes que cualquier otra cosa los reyes castellanos habían logrado convertir a las ciudades en circusncripciones fiscales al servicio de la hacienda regia ${ }^{(5)}$.

La anulación del poder solidario de los concejos y, por consiguiente, de sus órganos esenciales de expresión -Cortes y Hermandades- iba a ser necesariamente más lenta y paciente. A lo largo de los siglos XIV y XV, partiendo del Ordenamiento de Justicia de Pedro I, los Trastámara conseguirían reorientar las Hermandades castellanas hasta convertirlas en el primer ejército permanente al servicio de las empresas regias ${ }^{(6)} \mathrm{y}$, lo que es más importante, en una fácil y dócil fuente de recursos para la Corona ${ }^{(7)}$. Por lo que respecta a las Cortes, es un hecho suficientemente conocido que éstas, ya desde el siglo XV, se habian convertido en un simple mecanismo de voto de subsidios controlado desde la Corona.

En apenas dos siglos los regímenes municipales castellanos habían sido profunda y radicalmente transformados, adaptados finalmente a las necesidades del naciente Estado Moderno ¿A qué pudo deberse la relativa "facilidad" de un éxito tan rotundo? A mi juicio, la Corona desarrolló una estrategia que difícilmente podía estar destinada al fracaso. Los monarcas, a quienes en un primer momento interesó ceder graciosamente a las ciudades privilegios y franquezas, nunca renunciaron del todo a la posesión de un último resorte de intervención en los concejos. Desde finales del siglo XIII, dicho resorte, todavía útil, se puso en marcha con un único fin y con un sólo resultado posible. El primer intento en este sentido corresponde a Alfonso $X$, cuyo Fuero Real pretendía, entre otras cosas, sentar precedentes en torno al nombramiento regio de ciertas magistraturas urbanas. Pero indudablemente el gran hito de este proceso de mediatización corresponde a la consolidación de los regimientos por Alfonso Xl.

Es indudable que los monarcas castellanos jamás hubjeran salido victoriosos en su estrategia de no haber sido capaces de construir a su imagen y semejanza, y en función de sus únicos intereses, un modelo de relaciones entre Corona y municipios. A este respecto, D. Menjot ha afirmado "l'Etat central renforce son pouvoir sur la ville à travers son administration territoriale, l'exercise des fonctions étatiques et le contrôle du gouvernement municipal'(8). Es sobre todo este último punto el que nos interesa. Apelar a la vieja presencia del Palatium ya no era posible en el siglo XIII, la Corona necesitaba construirse una marco de relaciones nuevo. Para ello acudió no a abortar sino a canalizar en su propio beneficio una vez más los procesos que venian produciéndose en el mismo seno de las comunidades urbanas. Con fundamento en las bases de riqueza esenciales de cada ciudad y en los distintos resultados de las pugnas internas por el poder había ido generándose en cada ciudad un proceso de "selección natural" que acabó configurando con el tiempo en cada entidad urbana una élite de poder característica. A mediados del siglo XIV, Alfonso XI iba a sancionar institucionalmente este proceso mediante el Ordenamiento de 
todos conocido que creaba el sistema de regimientos. Su fundamental consecuencia fue, sin lugar a dudas, la delegación por parte del rey del poder municipal en manos de una élite de patricios urbanos, que a partir de entonces evolucionarían, sentando las bases de una poderosa clase política denominada tradicionalmente oligarquía ciudadana.

La consolidación de estos gobiernos oligárquicos vino a trastocar el orden imperante hasta el momento, no sólo en el sistema mantenido en las relaciones entre dichas ciudades y la Corona, sino también en el propio régimen de poder interno vigente en el seno de dichas sociedades urbanas. A partir de ahora se inauguraba una nueva fase en las relaciones entre poder central y poder municipal: los intentos por absorber el sistema gubernamental ciudadano, protagonizados por la monarquía, iban a plantearse en los términos que impusiera el cariz que adquirieran en cada momento las relaciones entre la oligarquía municipal y la Corona; asimismo, para las ciudades, el establecimiento del régimen oligárquico de gobierno suponía a todas luces una considerable ventaja. Esos miembros de la ciudad -en quien ahora se delegaban legítimamente las tareas de gobierno de la misma- representaban para las comunidades municipales la mejor garantía a fin de asegurar el régimen de privilegios a través del cual se pretendía consolidar de forma definitiva el ejercicio pleno de las llamadas libertades urbanas. Porque, en última instancia, este régimen de privilegios dependía de la capacidad negociadora que fuera capaz de desplegar la ciudad frente al poder constituido. $Y$ en este sentido, nadie mejor que la élite de poderosos para establecer términos ventajosos en dicha negociación.

Asi pués, en esta línea de pensamiento, es factible afirmar que el establecimiento del gobierno oligárquico como sistema de ejercicio del poder en la ciudad representó, tanto para la Corona como para la élite urbana, la posibilidad de beneficiarse mutuamente, lo que contribuyó a la consolidación de dicho sistema de gobierno, pese a que paradójicamente los intereses de ambas fuerzas se hallaran en principio encontrados: mientras que mediante dicho sistema la ciudad perseguía el afianzamiento de su régimen de libertades, la Corona no buscaba sino destruirlo. A este respecto, A. Rucquoi ha dicho lo siguiente: "la Couronne a favorisé systématiquement un groupe social au détriment des autres et, à travers lui, peut intervenir dans la politique urbaine. Dans cette perspective, toute "récuperation" de pouvoir et d'autonomie par les Concejos ne serait en fait qu'une "concession" faite par la Couronne à un groupe qu'elle contrôle"( ${ }^{\prime(9)}$. Asi, para conseguir su objetivo último, la destrucción de régimen de libertades urbano, a ésta le bastaba con cubrir convenientemente dos simples estrategias: romper, en primer lugar, la cohesión del grupo oligárquico y provocar asi la disfunción de todo el sistema mediante una política adecuada de acrecentamiento de oficios y de nombramiento directo de cargos ciudadanos $^{(10)} ; \mathrm{y}$, en segundo lugar, lo que nos interesa especialmente en el presente trabajo, arbitrar un sistema de mediatización adecuado a las nuevas instituciones urbanas. $Y$ aqui es donde cobra una papel definitivo la figura de los corregidores y asistentes que pretendo analizar. "Desde entonces -ha afirmado $H$. Casado- el 
intervencionismo regio se incrementará en la vida municipal en un proceso que se inició con el nombramiento de los regidores y se incrementó luego con los corregidores ${ }^{\mathrm{n}(11)}$.

Definido hace tiempo por Albi como representante del rey que debía en principio someterse a la voluntad de la mayoría del Regimiento, pero a quien "se le concedía en la práctica una amplísima libertad para proceder con arreglo a la suprema conveniencia del Estado y del interés público"(12), el corregidor castellano -a diferencia de las relaciones Corona-municipios en la Baja Edad Media- goza en la actualidad de un mas que suficiente acopio bibliográfico ${ }^{(13)}$. Ello podría, a simple vista, convertir en reiterativo cualquier nuevo título al respecto. Sin embargo, pese a haber sido analizado desde ópticas pretendidamente diversas, no es menos cierto que la casi totalidad de las mismas poseen un enfoque mayoritariamente institucional -entendido en su dimensión más estática-, y ello ha impedido hasta el momento proporcionar a dicha figura una verdadera inserción en la dinámica del proceso político que caracteriza a la Castilla del siglo XV y que conduce a la génesis y consolidación de la primera fórmula de Estado Moderno.

Nada más lejos de mi intención, pues, que insistir nuevamente sobre los aspectos "institucionales" que definen y caracterizan al corregidor castellano bajomedieval. La importancia de las páginas que seguirán radicará en destacar -en la medida en que se cumplan los objetivos propuestos- el verdadero significado, progresión y efectividad de la política de corregidores como instrumento de la estrategia regia destinada a la absorción y transformación de los poderes municipales, preámbulo imprescindible para la construcción del llamado Estado Moderno.

Para ello me propongo aplicar la siguiente plantilla de análisis a los casos comparados de Burgos y Cuenca. En primer lugar, me centraré en intentar establecer la verdadera progresión de la política de corregidores en el siglo XV a través de dos baremos: la estrategia regia a este respecto, es decir, la frecuencia, oportunidad y argumentos que los diferentes monarcas utilizan y su efectividad, medida en términos de la oposición ciudadana, sus límites y características. En segundo lugar, me interesa saber hasta qué punto el nombramiento de corregidores (o asistentes) respondió al objetivo de la Corona de mediatizar los gobiernos urbanos. En pocas palabras trataré en este segundo momento de medir la eficacia de estos oficiales en términos de ejercicio, competencias y absentismo en el cargo.

Finalmente, una última precisión. Hace tiempo que el análisis comparado de las realidades de Burgos y Cuenca viene constituyéndose en objeto preferente de mi línea de investigación ${ }^{(14)}$. Ello es asi por dos razones fundamentalmente que también son de aplicación en este caso. Primero, porque soy de la opinión que sólo los estudios comparativos permitirán delimitar los tipos de sistemas urbanos que sin duda coexisten en la Castilla bajomedieval y, lo que es más importante, especificar su dinámica estructural y evolutiva. $Y$, segundo, porque creo que las condiciones de su consolidación como núcleos urbanos, su propia estructura político- 
económica y, sobre todo, el sustrato socio-económico de cada una de sus oligarquías, hacen de Burgos y Cuenca dos sistemas urbanos claramente diferenciados, pudiéndose constituir cada uno de ellos en un significativo ejemplo, representativo de todo un conjunto de ciudades con características similares y que, a muy grandes rasgos, representan dos áreas geográficas separadas por la línea del Duero.

\section{LA PROGRESION DE LA POLITICA DE CORREGIDORES EN EL SIGLO XV}

Si pretendo descubrir hasta qué punto la figura del corregidor castellano fue uno de los principales instrumentos de los monarcas Trastámara en orden a la completa y efectiva mediatización de los gobiernos urbanos bajomedievales, las primeras variables que deberé medir -al margen de su efectividad, que dejaré para más adelante- serán: si realmente fue una medida adoptada frecuentemente por dichos monarcas, la estrategia seguida por estos en su imposición y las claves y dimensiones de la oposición que encontraron en la aplicación de dicha medida. En definitiva, la progresión seguida por la política de corregidores en el siglo XV.

\section{* Frecuencia de la imposición y claves de la estrategia regia:}

Según E. Mitre, el primer monarca en manifestar su voluntad centralizadora mediante el envío de corregidores a los distintos municipios de la Corona de Castilla fue Alfonso $\mathrm{XI}^{(15)}$. Pionero en muchos aspectos de la mediatización de los gobiernos municipales, también en este campo inició una política de la que se harían herederos incondicionales los monarcas de la dinastía Trastámara y que culminaría "institucionalizándose" definitivamente durante el reinado de los Reyes Católicos. La progresión de dicha política y los argumentos y pretextos utilizados en los años de su consolidación son el objetivo a desentrañar en el presente apartado.

De la realidad vertida en las fuentes documentales conquenses y burgalesas del siglo XV se deduce la siguiente progresión cuantitativa: a lo largo del período estudiado, se detecta la presencia en Cuenca de corregidor real en más de veinticinco años, frente a sólo diez años en Burgos. En esta última ciudad se produce además el caso significativo de que seis de dichos años se inscriben en el reinado de los Reyes Católicos, reduciéndose a cuatro, por consiguiente, los años que a lo largo de tres cuartos de siglo detectan la presencia de corregidor en Burgos. Por el contrario, en Cuenca la proporcionalidad entre reinados anteriores y Reyes Católicos es mayor, dándose sólo el factor de una mayor continuidad secuencial en el caso de los años coincidentes con el reinado de Isabel y Fernando que, además, son aquellos en los que poseemos la serie más continuada de documentación municipal. 
Al margen de las diferencias percibidas entre las cifras resultantes de la realidad burgalesa y conquense -sobre las que más adelante volveré para explicarlas- parece claro que el final de la centuria, más concretamente el reinado de los Reyes Católicos representa en casi todas las ciudades una continuidad y frecuencia sin parangón anterior en el nombramiento e imposición de corregidores. En este sentido podríamos hablar de una progresión ascendente en términos puramente cuantitativos.

El dato en sí no es sorprendente ni nuevo ${ }^{(16)}$, pues es sabido que en todos los frentes el reinado de los Reyes Católicos supone la culminación definitiva de la política de centralización iniciada prácticamente desde mediados del siglo XIII. Lo que si es significativo es que dicha progresión sea continuadamente ascendente a lo largo del siglo $\mathrm{XV}$, incluidos los períodos de debilidad monárquica coincidentes con los reinados de Juan II y Enrique IV que prácticamente ocupan la casi totalidad de la centuria. Desde la extensión del régimen de corregidores bajo el reinado de Enrique III, la frecuencia en la imposición de los mismos por la Corona no detecta ninguna tendencia a la baja. Juan II designará más corregidores que su inmediato predecesor, e idéntica política llevará a cabo su hijo Enrique $\mathrm{IV}^{(17)}$. Las razones de esta mantenida progresión ascendente, asi como las que explican las diferencias que separan la aplicación de la política regia en Cuenca y Burgos, deben buscarse no sólo en las claves de la estrategia regia, sino también en las dimensiones y características de la oposición ciudadana. Por el momento nos ocuparemos de la primera para inmediatamente después abordar la segunda.

Según Bermúdez Aznar, "...la última razón de ser del corregidor castellano debe buscarse en una concreción en la realidad institucional de la Corona de las prerrogativas correctoras que sobre la colectividad tiene el rey o príncipe soberano"(18). Efectivamente, los monarcas castellanos siempre se reservaron un último resorte de actuación que les capacitara legalmente para intervenir en los asuntos internos de los gobiernos municipales. Desde mediados del siglo XIII dicho resorte se había puesto lentamente en marcha con mayor o menor efectividad $y$, por supuesto, el nombramiento de corregidores constituía un elemento clave del mismo. Sin embargo, no todo consistía en reclamar por parte de la Corona el derecho a "arbitrar" o, mejor, "corregir" los asuntos internos de los municipios, sino que era necesario conseguir que dicha reclamación no obtuviera el rechazo frontal de las ciudades y entrara, por consiguiente, en una via muerta. De ahi la necesidad de diseñar una correcta estrategia, sobre todo en aquellas ciudades especialmente "resistentes" a las injerencias regias.

Básicamente, dicha estrategia no podía consistir en otra cosa sino en lograr que poco a poco lo que en inicio era un oficial extraordinario,justificado en ese derecho a "corregir" al que nunca renunció el monarca, se convirtiera en un cargo municipal ordinario, institucionalizando asi de derecho la presencia activa de los oficiales regios en la gestión interna de los municipios ${ }^{(19)}$. Los datos cuantitativos anteriormente explicados, indicadores de una mayor continuidad secuencial 
a finales del siglo XV, demuestran que dicha estrategia ha alcanzado plenamente sus objetivos en época de los Reyes Católicos.

Independientemente de ciertos factores ya resaltados en otros estudios como coadyuvantes en el proceso de absorción de los resortes municipales por la Corona ${ }^{(20)}$, que también contribuyeron a la consolidación de la presencia de corregidores en los municipios castellanos del siglo XV, parece claro que los monarcas aprovecharon escusas de diversa índole, preferentemente la existencia de desórdenes o alteraciones del orden público más o menos descontroladas, con el fin de "justificar" el envío ocasional de estos oficiales correctores. Los datos que se detectan en las fuentes conquenses y burgalesas son taxativos a este respecto.

En 1428 el nombramiento de corregidor en Cuenca viene precedido de la existencia en la ciudad de "çiertos bulliçios" que, primero obligan a que el concejo designe un procurador especial (Francisco de Iranzo) encargado de defender los derechos de Cuenca ante el rey "contra todos quantos soliçitan corregidor"(21) y, después, hacen necesario que los regidores requieran a los alcaldes para que investiguen lo que ocurre e indaguen sobre la existencia de "rufianes y vagabundos" a fin de prenderlos y aplicar las penas conforme a la ordenanza municipal al respecto ${ }^{(22)}$. Otro tanto ocurre en el año 1459. Por estas fechas, el nombramiento de Pedro de Ulloa como corregidor de Cuenca ${ }^{(23)}$, viene precedido en los meses anteriores de varios desórdenes que han obligado a tomar medidas excepcionales. El 29 de septiembre, los alcaldes, guarda mayor y regidores de Cuenca, "ante los escandalos acaesçidos en la çibdad" juran colaborar a favor de la justicia y no apoyar a los responsables de los bullicios, "non obstante qualesquier ligas, confederaçiones, juramentos, pleitos omenajes e otras qualesquier fuerças e fyrmesas que en contra de los susodicho....ayan fecho"(24). Aproximadamente un mes más tarde, el 12 de noviembre, para prevenir el hecho de que algunos "caballeros y regidores" tenían "rufianes y vagabundos", protagonistas de los escándalos, fue necesario ordenar que nadie en la ciudad tenga más de cuatro hombres de pie y que ninguno de ellos sea "rufián"(25).

Los casos documentados en Burgos son, todavía, más esclarecedores. El 27 de marzo de 1411 Juan Sánchez de Ubeda, bachiller en leyes y alcalde mayor de la reina, presenta en el Regimiento burgalés una carta del rey, firmada de la reina y fechada en 17 de marzo del mismo año ${ }^{(26)}$, por la que, con motivo de los conflictos surgidos en Burgos por los que se llegó incluso a suspender a los alcaldes en sus oficios ${ }^{(27)}$, se le nombra corregidor de esta ciudad. Pedido su cumplimiento, los oficiales burgaleses respondieron con la fórmula habitual de que la obedecían pero que sobre su cumplimiento darían respuesta más adelante ${ }^{(28)}$ y todavía se hallaban en esta situación el 30 de marzo ${ }^{(29)}$, día que fue finalmente aceptado ${ }^{(30)}$. Que las luchas internas y los desordenes provocados por su causa fueron el pretexto de la Corona para el envío de este corregidor queda claro cuando, pese al nombramiento de Juan Sánchez de Ubeda, el asunto ha requerido de una pesquisa llevada a cabo por dos enviados especiales del rey, Alfonso 
Rodríguez y Juan Fernández de Asero, y sólo tras la misma, ya el 28 de junio, son restituidos en su oficio los alcaldes de Burgos, suspendidos por lo mismo meses antes ${ }^{(31)}$. Asimismo, el nombramiento de Gómez Manrique como corregidor en 1463 es expresamente justificado por Enrique IV de la siguiente manera:

"....Vien sabedes los escandalos peleas e rroydos e muertes de omes que agora de poco aca en esa çibdad son acaesçidos, e los crymines e delitos que en ella se han fecho e cavan de faser e cometer, lo qual non ha seydo nin es punydo nin castigado por mengua de justiçia, por lo qual mi merçed es, entendiendo ser asy conplidero a my serviçio e a esecuçion de my justiçia e al bien e pro comun e paz e sosiego de esa çibdad e su tierra, e porque de agora en adelante en ella la dicha mi justiçia se esecute como deve e los tales escandalos e ynconbenientes çesen, que Gomes Manrrique, my vasallo e del my consejo, aya e tenga por my el ofiçio de corregimiento e judgado de esa çibdad..." (32)

También en este caso, los desórdenes, provocados por el secular enfrentamiento de la ciudad con los Stúñiga, alcaides de la fortaleza de Burgos, fueron debidamente solucionados por la pesquisa del doctor Alonso de Paz, una vez que el Regimiento hubiera tomado medidas excepcionales de presión para ello ${ }^{(33)}$. Por consiguiente, de nuevo fueron tomados como escusa para la designación de un corregidor en una ciudad que tradicionalmente había desarrolado una fuerte oposición a dicho oficial.

Por el contrario, las fórmulas empleadas por los Reyes Católicos ya desde el inicio de su reinado permiten descubrir que los pretextos han sido definitivamente olvidados. Incluso en Burgos, el nombramiento de Rodrigo de Valderrábano como corregidor va precedido del escueto "nos entendiendo ser asy cunplidero a nuestro serviçio e a execuçion de la nuestra justiçia e al pro e bien comun de esta dicha çibdad e su tierra" ${ }^{\text {(34) }}$.

El reinado de Isabel y Fernando cierra, como en todos los demás procesos que conducen a la primera fórmula de Estado Moderno, la trayectoria que a lo largo del siglo XV hizo posible la conversión de los corregidores castellanos -de nombramiento hasta ese momento ocasionalen oficiales ordinarios y permanentes. Las alteraciones frecuentes del orden público urbano, motivadas por las cotidianas luchas de facciones, la resistencia frente al establecimiento de un monopolio de poder o las dificultades de las autoridades municipales para el mantenimiento del orden y la justicia, proporcionaron a los diferentes monarcas de la dinastía Trastámara el pretexto necesario para "corregir" las deficiencias de los gobiernos urbanos. Sin embargo, los éxitos de la estrategia regia no pueden ser entendidos en su totalidad sin analizar y calibrar paralelamente las verdaderas dimensiones y características de la oposición ciudadana.

\section{* La oposición ciudadana: sus límites y características:}

Hace más de un siglo, Cascales afirmaba que la introducción de los corregidores en las ciudades castellanas se debió a que muchas de ellas primaron sus propios intereses frente a los de la Corona, abandonando asi 
el correcto ejercicio de la justicia ${ }^{(35)}$. Muchos años antes, Alonso de Palencia, juzgaba así la política seguida por Enrique IV con los corregidores: "...resuelto D. Enrique a romper con toda honradez, con tal de agenciar riquezas para sus favoritos, repartió por las ciudades ciertas autoridades con título de corregidores, y que mejor debieron llamarse merecedoras de corrección.." (36). Independientemente de que la razón fuera la desidia interesada de las ciudades en hacer valer la justicia, o la maldad de los reyes, más afanados en ganar lealtades a costa de sus súbditos que en promover el bien común, lo cierto es que la breve conversión del corregidor en un oficial de habitual y continua presencia en las ciudades dependió en cierto modo de las dimensiones y características de la resistencia desarrollada por las mismas, o mejor, por sus grupos dirigentes.

Nadie duda de que dicha resistencia existió. E. Mitre ha hecho un serio repaso a todas y cada una de las presuntas cortapisas que plantearon una y otra vez los ciudadanos a lo largo de todas las Cortes Generales celebradas en el siglo $X V^{(37)}$. Sin embargo, los éxitos de la estrategia regia sólo pueden explicarse íntegramente desde la perspectiva de una poco seria o inoperante (deberemos descubrir si consciente o inconsciente) oposición ciudadana. Es más, la diferencia de intensidad o de intencionalidad de dicha oposición sería el factor principal que explicaría el por qué de las diferencias anteriormente apuntadas entre Burgos y Cuenca.

A este respecto A. Bermúdez Aznar ha afirmado lo siguiente: "..la oposición que encontró en las distintas localidades castellanas este intervencionismo regio no dejó de ser muy importante en algunas ocasiones pero, con excepciones, podría calificarse en general de discreta. $Y$ es evidente que la carencia de argumentos teóricos que oponer a dicha intervención...no parece que sea el único argumento capaz de explicar tal actitud; por el contrario, todo hace pensar que la causa última hay que referirla a los propios intereses de los protagonistas de la vida urbana: sus oligarquías". Y más adelante completa la explicación: "..sus agentes (los del rey) tendieron a garantizar el mantenimiento de los marcos institucionales en que debían moverse los grupos urbanos dominantes, haciendo valer su prestigio, cuando no sus instrumentos de poder, para hacer frente a las injerencias nobiliarias y revueltas populares. Se explica así la condescendencia o tolerancia de las élites urbanas respecto al intervencionismo del poder real" ${ }^{\prime(38)}$. Asi pues, las razones del éxito de la política regia de corregidores deberían buscarse en el consentimiento pasivo de los grupos dirigentes urbanos, a quienes, en última instancia no perjudicaría y si beneficiaría dicha política. Una vez más se demuestran las ventajas que el sistema de poder oligárquico reportó a la Corona en la Baja Edad Media. La tesis nos parece lo suficientemente interesante para intentar precisarla y desarrollarla.

Si analizamos a grandes rasgos las características de la oposición ciudadana percibimos que el argumento fundamental, alegado con cierta frecuencia, siempre se refiere a los costos adicionales en dinero que implica la presencia de un corregidor en la ciudad ${ }^{(39)}$. Es cierto que el salario que el 
monarca obliga a pagar a los mismos es elevado ${ }^{(40)}$, pero también es verdad que las ciudades raramente se ven en apuros para pagarlos, disponiendo de numerosos recursos adicionales para ello ${ }^{(41)}$. Por lo general, los problemas a este respecto nos ponen en contacto con motivaciones y razones de índole muy diferente. A este respecto es muy significativo el hecho de que en Burgos en el año 1464, Gómez Manrique, hasta ese momento corregidor en dicha ciudad, vea prorrogado su cargo en la misma como asistente -oficial con menor capacidad mediatizadora- pero con el mismo salario que tenía asignado como corregidor ${ }^{(42)}$. El caso más significativo a este respecto es el ocurrido en Cuenca en 1457 con el corregidor Diego Fernández de Vergara.

A lo largo del año 1457 Cuenca protagonizaría una de las raras y escasas ocasiones de claro enfrentamiento con un corregidor regio, Diego Fernández de Vergara. La escusa es el pago de su salario, pero el debate esconde algo más profundo, nada más ni menos que las propias disensiones internas existentes entre los diferentes grupos que se disputan el poder en Cuenca. Dicho planteamiento está claro prácticamente desde el comienzo de los problemas. En junio de 1457, ante el requerimiento presentado por el alguacil designado por el corregidor sobre el pago del salario correspondiente a este último ${ }^{(43)}$, ciertos regidores, Martín García de Sacedón, Gonzalo Núñez de la Muela y Juan de Molina, habían procedido al repartimiento de dicho salario entre los vecinos de Cuenca y su tierra. Dicho acto era denunciado en ayuntamiento por el regidor Alonso del Castillo, alegando que habían ido contra la decisión ya tomada de no pagar el salario al corregidor Vergara - hasta que éste "torne los muchos cohechos que ha llevado"- por cuanto se había ausentado de la ciudad ${ }^{(44)}$. Inmediatamente, los regidores implicados en dicha acusación presentaron un escrito de alegaciones en el que se explicaba lo siguiente: en primer lugar, que en lo referente a los "cohechos" del corregidor se había presentado al rey la correspondiente petición, sobre lo que no había más remedio que esperar y, en segundo lugar, en cuanto al salario de los días que estuvo ausente, ya se decidió pagar una cantidad debido a que dichas ausencias se produjeron cuando Diego Fernández de Vergara fue a la corte a representar a la ciudad, y a petición de la misma, en el contencioso mantenido por esta referente a los vasallos de Cuenca que el rey cedió a Rodrigo Manrique ${ }^{(45)}$.

Entre junio y octubre se suceden las presiones para el pago íntegro del salario del corregidor. Estas se presentan en términos de cartas reales al respecto y requerimientos en forma del propio Diego de Vergara o de sus representantes ${ }^{(46)}$. La victoria inicial corresponde al sector que se niega a aceptar las presiones regias. Trás movilizar el interés público y presentar un largo escrito en que los vecinos de Cuenca y su tierra refieren detalladamente los "cohechos" y abusos de que han sido objeto por parte del corregidor y de sus hombres, el 5 de noviembre el concejo de Cuenca responde que no pagará el salario a Diego de Vergara pese a las cartas reales que insisten sobre ello ${ }^{(47)}$. Con el objeto de salir de la via muerta en que había entrado el conflicto, los regidores y el corregidor deciden ponerse en manos de unos "jueces arbitros" designados por ambas partes, 
nombrando a tal efecto al obispo Lope de Barrientos ${ }^{(48)}$. Paralelamente el rey envía a Juan de Mendoza como pesquisidor en Cuenca con el fin de dirimir los "debates" entre la ciudad y el corregidor ${ }^{(49)}$. Finalmente, la postura regia se impone. La sentencia del obispo, ya dictada el 2 de marzo, es favorable al corregidor $^{(50)}$. El 14 de abril Cuenca se obliga a pagar al corregidor lo que le correspondía en virtud de la sentencia dada por el obispo ${ }^{(51)}$.

Asi pués, la insistencia y exclusividad con que una y otra vez las ciudades acuden al inoperante e ineficaz argumento del dinero para justificar la oposición a los corregidores designados por el rey podría demostrar, a mi juicio, dos cosas: en primer lugar, que en realidad no existe ninguna otra base legal que pueda ser argumentada en contra de dicha práctica regia; en segundo lugar, que realmente, las oligarquías urbanas, o al menos un sector de las mismas, están más interesadas en la presencia de los corregidores de lo que a primera vista parece deducirse de la documentación.

En lo referente a la primera de ellas podría ser, sin duda, una hipótesis a tener en cuenta. En cierto modo serviría para explicar algunos de los aspectos del por qué la ingerencia regia es más completa y fácil en aquellas ciudades a quienes las "libertades" les fueron cedidas graciosamente por la Corona desde mediados del siglo XII, como por ejemplo Cuenca, que en aquellas donde dichas "libertades" fueron en cierto modo "ganadas". Es un hecho evidente que, a diferencia de lo ocurrido en Burgos, la normativa legal sobre la que se edifica el sistema de poder conquense, otorga al rey, teóricamente en los comienzos y de forma práctica al final de la Edad Media, la última palabra en los asuntos de gobierno. Sin embargo, pese a admitir que este hecho proporciona a Cuenca una mayor "vulnerabilidad" frente a las injerencias regias, creo sinceramente que la explicación más completa proviene, sobre todo, de tener fundamental y principalmente en cuenta el diferente carácter y composición de sus respectivas oligarquías y, por consiguiente, de la distinta actitud que frente a los corregidores presentaron unas y otras. Asi pues, las claves y características de la oposición ciudadana -encuadrada ésta en su marco adecuado: la oligarquía correspondiente- son un factor imprescindible a la hora de calibrar la verdadera progresión y éxito de la estrategia regia en el nombramiento de corregidores, dependiendo ésta, en última instancia, de una verdadera oposición o de una encubierta connivencia.

Rastrear en la documentación una posible connivencia entre la política de nombramiento de corregidores y los intereses de las oligarquías urbanas no resulta siempre fácil. En el presente caso, dicha presunta connivencia puede detectarse indirectamente a través de los siguientes datos significativos:

En primer lugar, las presuntas alteraciones del orden público que dan lugar al nombramiento regio de un corregidor, aceptado o no aceptado, demandado o no demandado por la correspondiente oligarquía local, y que persisten, incluso, una vez que dicho oficial se haya desempeñando su cargo, siempre esconden -tanto en Cuenca como en Burgos- graves 
disensiones internas, bien entre los miembros de la propia oligarquía, bien entre los grupos instalados en el poder y los marginados del mismo.

En Cuenca esto se aprecia claramente en varias ocasiones: en 1432, el corregidor, Andrés González del Castillo, daña los derechos de caballeros y escuderos de Cuenca al arrendar las "entregas de fuero" de los cristianos y judíos, imponiendo que las mismas sean dadas a quien el designase ${ }^{(52)}$. Entre 1435 y 1436, con motivo de la deposición de Rodrigo de Bobadilla como corregidor de Cuenca, el juez pesquisidor enviado al efecto, Gutierre Muñoz, suspendió el derecho de las vecindades a designar ciertos oficios de fuero -alcaldías y alguaciladgos- nombrando a sus oficiales para ello y dando lugar a un largo contencioso con ellas ${ }^{(53)}$. Parece claro que en Cuenca los corregidores y delegados reales contribuyen en muchos casos a fortalecer a la oligarquía dominante como grupo bien asentado en el poder contra los aspirantes, marginados del mismo. A través de dichos oficiales se canaliza una de las tensiones sociales más evidente de la Cuenca bajomedieval: la "nobilización" del concejo y el rechazo de su sistema al ascenso sociopolítico de los grupos sociales y profesionales enriquecidos. La "connivencia" entre corregidores y oligarquía activa en Cuenca es, a veces, más que evidente. En 1482, Alonso Téllez de Cabrera, corregidor de Cuenca, acuerda "pagar a los regidores por haberle dado su voto como procurador en Cortes" y para cumplirlo da como fiador a su primo Diego de Montemayor ${ }^{(54)}$.

En Burgos también se constatan argumentos de esta índole. En 1426 , hay noticias ciertas sobre que "algunos demandan al rey corregidor" con motivo de las luchas que enfrentan desde hace tiempo a oficiales del Regimiento y "vecindades". Dichas luchas desembocarán en la sentencia arbitral, dada por el conde de Castro, por la que se regula la participación del "común" de Burgos en la administración y gobierno de la ciudad y se institucionaliza en esta ciudad definitivamente el sistema oligárquico para el ejercicio el poder ${ }^{(55)}$. Nuevos enfrentamientos con las vecindades provocan situaciones parecidas en 1446 y $1450^{(56)}$. En 1432 y 1463 fueron las luchas entre sectores de la oligarquía burgalesa y el alcaide de la fortaleza de Burgos las causas de la demanda de corregidor ${ }^{(57)}$. Estos datos son tanto más significativos cuanto que sabemos que alteraciones del orden público en las que no se hallan implicados los diferentes sectores sociales de la ciudad y que responden únicamente a circunstancias de delincuencia común nunca sirven de apoyo a ninguna demanda de corregidor, solucionándose frecuentemente con una alianza entre todas las fuerzas activas de la ciudad, alcaldes, regidores y vecindades ${ }^{(58)}$.

Sin embargo, pese a poder constatarse en Burgos y en Cuenca situaciones similares, existe un hecho muy significativo que contribuye a diferenciarlas. Mientras que en Cuenca, las disensiones sociales internas derivan siempre en el nombramiento de un corregidor, en Burgos suelen adoptarse medidas alternativas que evitan el nombramiento de este último. O bien se llega a un acuerdo entre partes que pone el problema en manos de jueces árbitros, como en 1426, o bien dan lugar a una alianza entre 
regidores y alcaldes con el fin de neutralizar fuerza políticas ajenas, como en 1432. En todos los casos, salvo en 1463, logra evitarse en Burgos la presencia de un corregidor. No creemos que ello se deba simplemente a las diferencias que separan a los distintos mecanismos institucionales del sistema conquense y del burgalés, aptos unos y "difíciles" los otros para la mediatización regia, sino a razones de índole más profunda directamente implicadas en la propia constitución y características de sus respectivas oligarquías.

Mucho antes de que la evolución institucional sancionara definitivamente en Castilla el "cierre" de los patriciados, venía produciéndose en el seno de las comunidades urbanas una especie de "selección natural" que acabaría configurando con el tiempo en cada ciudad una élite de poder característica. Dicha selección y su resultado final dependen, en primer lugar, de las bases de riqueza fundamentales en cada ciudad y, en segundo lugar, de los resultados concretos de las pugnas internas. Asi, en unas ciudades la oligarquía será el resultado de la pugna por la riqueza mobiliaria, y los mercaderes accederán tempranamente al poder. En otras se creará un sustrato mixto, en el que convivirán antiguos hidalgos y artesanos o mercaderes enriquecidos. En un tercer grupo, la nueva clase surgida a raíz del desarrollo comercial, pese a repetidos y enconados intentos, jamás logrará alcanzar defintivamente el poder.

Burgos pertenece al primero de los casos arriba señalados. Todo el sistema de poder burgalés se construyó y configuró en torno a una élite tempranamente "seleccionada" por la indiscutible vocación mercantil de la ciudad. Ello hizo que, ya en la Baja Edad Media, la característica más acusada de la oligarquía burgalesa fuera su homogeneidad. Homogeneidad que se manifiesta en la posesión de objetivos económicos comunes, en la similitud de formas de vida, en el cuidado por las formas externas de significación social, en la fundación de cofradías y asociaciones reservadas para los miembros de la élite y, en definitiva, en la igualdad de aspiraciones sociales. Sólo esta homogeneidad podía permitir la invulnerabilidad del sistema, porque sólo la solidaridad de clase, cristalizada en una fuerte conciencia oligárquica, hace que el control interno de los mecanismos de poder se constituya e la pieza clave de todo el sistema. Sin dicho control no existiría el sistema y, por ende, tampoco la oligarquía.

Por el contrario, Cuenca se halla en el último de los casos arriba reseñados. En este bloque de ciudades, la rápida aristocratización de la caballería villana provocará desde mediados del siglo XIII su asimilación a la baja nobleza y su integración en la clase feudal. De algún modo la guerra, "factor extaeconómico", actuó como detonante de la selección y consiguió perpetuar una dinámica interna y una estructura de poder que permitió a los propietarios rurales controlar el acceso a las magistraturas municipales y perpetuarse en ellas y, lo que es más importante, impedir a partir de ese momento la inclusión de cualquier "novedad" capaz de alterar el proceso de evolución. Cuando por efectos de la aplicación del proyecto político de la Corona se produzca, aproximadamente en la primera mitad del 
siglo XIV, la sanción legal de estas oligarquías, en ciudades como Cuenca dicha sanción legal operará sobre procesos no culminados de selección natural. Poco a poco el inevitable desarrollo económico de la ciudad hará surgir nuevos grupos sociales enriquecidos que actuarán como extraños a un sistema consolidado artificialmente en forma prematura. Ello servirá, a la vez, como elemento de tensión social y como via de disolución del sistema oligárquico. Provocará, en última instancia, conflictos sociales nunca definitivamnete resueltos y una posibilidad de acción para la Corona que servirá para neutralizar y diluir la solidaridad oligárquica y, por tanto, la efectividad del sistema.

\section{LA EFICACIA DE LA POLITICA DE CORREGIDORES EN EL SIGLO $X V$}

Constatado el hecho, y analizadas las razones, de la progresión continuadamente ascendente de la política regia de corregidores en el siglo $X V$, habrá de abordarse, para finalizar, la efectividad de dicha política, medida en los únicos términos en que esto puede hacerse: a través del grado de absentismo que afecta al ejercicio de los corregimientos castellanos en el siglo XV y mediante el análisis de las competencias ejercidas realmente por los corregidores regios en las ciudades castellanas de esta centuria.

De la documentación conquense y burgalesa del período parece deducirse que, aunque la presencia de los corregidores en las reuniones de concejo y ayuntamiento es frecuente cuando estos se hallan residiendo en la ciudad, su ausencia de la misma, con el consiguiente nombramiento de lugartenientes, se produce, asimismo, en numerosas ocasiones. $Y$ a este respecto se constata un hecho curioso y significativo. En los documentos que se conservan sobre condiciones de aceptación y "recibimiento" de corregidores en Cuenca y Burgos, la obligación de desempeñar personalmente el cargo y eliminar cualquier posible ausencia o absentismo en el mismo se convierte en una verdadera "piedra de toque" de la negociación municipal ${ }^{(59)}$. Otro tanto ocurre con las demandas de los procuradores en Cortes durante todo este período. Sin embargo es el propio rey el que manda llamar o "justifica" la ausencia de los corregidores del oficio para el que han sido expresamente designados ${ }^{(60)}$.

Parecería a primera vista que debería haber sido el rey el más interesado en controlar el absentismo de los corregidores, mientras que las ciudades deberian estar interesadas en su "desaparición", aunque sólo fuera temporal. Esta aparente paradoja se explica fácilmente si tenemos en cuenta los siguientes hechos: el nombramiento de lugartenientes, hecho constatado con amplísima frecuencia tanto en Cuenca como en Burgos ${ }^{(61)}$, garantiza el cumplimiento del principal objetivo de la Corona, la mediatización. Asimismo, a ésta le interesa casi más habituar a los municipios de la presencia continuada de un oficial regio, que el ejercicio 
efectivo de las competencias a éste asignadas, cubiertas, como queda dicho, por sus lugartenientes. Sin embargo, para las ciudades, ello significa desviar dinero para el pago de oficiales "ausentes" y dejar sin solución los problemas que han llevado a la aceptación del corregimiento, máxime cuando existe una connivencia clara y consciente entre los miembros de los grupos oligárquicos dirigentes y el corregidor. Todo quedará más claro al analizar las competencias y el ejercicio efectivo de las mismas por parte de los corregidores castellanos del siglo XV.

En 1502, los Reyes Católicos notifican a Cuenca el nombramiento de Fernando de Rebolledo como corregidor de esta ciudad con la justicia criminal y los oficios de alcaldía y alguaciladgo ${ }^{(62)}$. Parece claro que la teórica intencionalidad de los monarcas al nombrar corregidores en las ciudades es responsabilizarles de las competencias en materia de justicia campo que la doctrina política medieval asigna invariable e indefectiblemente al rey-, suspendiendo asi la subrrogación de la misma hecha anteriormente a las justicias municipales. Incluso, la documentación demuestra que esta "teórica intención" se ajusta a una realidad en la práctica. En Cuenca, el nombramiento de un corregidor implica la inmediata suspensión de los oficiales responsables del ejercicio de la justicia en la ciudad, significativamente pertenecientes a los oficios que por fuero se sortean anualmente entre las collaciones de Cuenca, alcaldes y alguacil ${ }^{(63)}$. Asimismo, en Burgos, las competencias que en ningún caso se le discuten al corregidor son las que afectan al correcto ejercicio de la justicia y el mantenimiento del orden público en la ciudad, dándose el hecho significativo de que en esta ciudad no se suspenden los oficios que en ella se encargan habitualmente de estas tareas, los alcaldes -que, a diferencia de Cuenca, son en este caso verdaderos miembros de pleno derecho de la oligarquía-, sino que mantienen intacto su ámbito de competencias ${ }^{(64)}$.

Lo hasta ahora dicho abundaría, pués, en la idea de que el ámbito por excelencia de competencias de los corregidores castellanos en el siglo $X V$ es el ejercicio, en nombre del rey, de la justicia en los diferentes municipios del reino. Sin embargo, dichas competencias se amplían en la mayoría de los casos hasta afectar claramente a los asuntos relativos al propio gobierno de la ciudad, desde la defensa del señorióo ${ }^{(65)}$, hasta la movilización de las milicias urbanas ${ }^{(66)}$. Este proceso sinuoso y sutil de ampliación sistemática de las competencias de los corregidores culmina definitivamente en época de los Reyes Católicos. Estos monarcas obvian la situación de hecho por la cual la presencia del corregidor "suspende" no sólo el ejercicio de la justicia sino la totalidad de las funciones de gobierno, dirigiéndose sistemáticamente al corregidor cuando deben comunicar cualquier asunto de la índole que sea a la ciudad: procedimientos internos de gobierno ${ }^{(67)}$, reglamentación de los oficios ${ }^{(68)}$, ordenación econó-mica ${ }^{(69)}$, fiscalidad, relaciones con la tierra ${ }^{(70)}$, etc.

Sin embargo, lo importante no es tanto el ámbito de competencias -y la extensión que del mismo hicieron los monarcas a lo largo del siglo XV-, sino su ejercicio efectivo en las ciudades a lo largo de esta centuria. $Y$ aqui 
de nuevo volvemos a tropezarnos con la connivencia consciente de las oligarquías urbanas y con las diferencias entre Burgos y Cuenca.

Todo demuestra que en Cuenca los corregidores constituyeron un efectivo apoyo para los grupos de poder oligárquicos frente a ciertas presiones de las poderosas casas nobiliarias circundantes y, sobre todo, frente a los grupos enriquecidos y constantemente marginados del poder. Numerosos datos avalan esta tesis. Las condiciones de aceptación de Pedro de Ulloa como corregidor en Cuenca en el año 1459 (Vid. nota no 59) no limitan para nada la acción efectiva de dicho oficial, sino las posibilidades de actuación contra los regidores de la misma, al tiempo que refuerzan la acción de estos últimos como único y exclusivo grupo de poder. En ellas se expresa textualmente la obligación por parte de Pedro de Ulloa de hacer pagar los mrs. contenidos en los repartimientos, guardar la ordenanza sobre los oficios acrecentados -que por otro lado ellos incumplen constantemente ${ }^{(71)}$, guardar la honra y preeminencias del guarda y regidores. Más claros todavía son los siguientes testimonios: en 1423, regidores y corregidores conjuntamente toman medidas de presión para defender el adehesamiento de la sierra de Cuenca, práctica que atenta contra todos los derechos de los pequeños campesinos que tradicionalmente explotan sus recursos y que generará a lo largo de todo el siglo XV tensiones entre la ciudad y los habitantes de sus aldeas, y contra los intereses de los señores de la zona entre ellos Diego Hurtado de Mendoza, quien protestará en repetidas ocasiones por ello ${ }^{(72)}$. Asimismo, en 1440 el corregidor es designado como "juez árbitro" en el debate entre la ciudad y los sexmos de Chillarón y Arcas y el arrendador de las monedas del año $1438^{(73)}$.

Por el contrario, algo totalmente distinto está ocurriendo en Burgos. En esta ciudad, cualquier demanda de competencias por parte del corregidor al margen de los asuntos que atañen al estricto cumplimiento de la justicia se ve seriamente dificultada cuando no impedida ${ }^{(74)}$. Asimismo, las condiciones con que en 1411 se recibe a Juan Sánchez de Ubeda y en 1465 a Gómez Manrique como corregidor y asistente de Burgos respectivamente (vid. nota $n^{\circ}$ 59) no dejan lugar a dudas. En ambos casos, la oligarquía burgalesa tiene como objetivo limitar el campo de actuación de estos oficiales en "su" ciudad. Si en el primero de los casos se le obliga a "librar los pleitos bien y lealmente", en el segundo se actúa con más contundencia. Por su interés, conviene reproducir íntegramente ciertos párrafos de dicho documento:

"Por quanto por parte de los señores del Rregimiento e çibdat de Burgos fueron e son demandados a Gomes Manrrique çiertas moderaçiones, que a el plugo asi de faser en algunos capitulos contenidos en las provisiones que el rrey nuestro señor le dio para en la asistençia de la dicha çibdad segund mas largamente pareçeria por unos capitulos que le dieron, los quales el otorgo por non dexar para adelante a la dicha çibdad non buena costunbre, pero lo conçertado e acordado non enbargante aquella rrespuesta que el entyende que puede moderar por contenplaçion de 
los dichos señores del ayuntamiento e de los procuradores de la dicha çibdad que sobre ello le han encargado es lo siguiente:

...Iten, por quanto en las dichas provisiones el rrey nuestro señor manda que el dicho Gomes Manrrique o su lugarteniente aya de estar o este en los ayuntamientos del Rregimiento de la dicha çibdad, e que sin el o el dicho su lugarteniente non se pueda faser ningund ayuntamiento e que si se fisiere que non vala nada de lo que fisieren e ordenaren, lo qual en alguna forma la çibdad ha por grave, a el plase por su contenplaçion que se modere en esta manera: que si en los dias de los martes e juebes e sabados, que son dias en que se acostunbran faser los dichos ayuntamientos, el dicho Gomes Manrrique o su lugarteniente non fuere a ellos o a alguno de ellos al lugar e oras acostunbradas, que en el tal caso los alcaldes e los rregidores que alli se açercaren, aviendo numero segund su costunbre, puedan hordenar lo que entendieren que cunple a serviçio de Dios e del rrey e bien de la çibdad que aquello sea valedero; pero si ocurrieren casos para que se ayan de ayuntar en dias e oras e lugar desacostunbrado que en tal caso non se pueda faser el ayuntamiento sin lo noteficar primero al dicho Gomes Manrrique e a su lugarteniente para que vayan a entender en el tal negoçio, pero si el o su lugarteniente non fueren al dicho ayuntamiento, que los dichos alcaldes e rregidores, aviendo numero de ofiçiales, puedan ordenar commo dicho es 10 que entendieren que cunple. E asy se entiende para en aquellas cosas que se rrequiere aver numero de rregidores segund sus ordenanças, que en las otras que non son de tanta inportançia el dicho Gomes Manrrique non se agraviara porque si nesçesidad ocurriere en ellas provean.

Yten, por quanto en las dichas provisiones el rrey nuestro señor manda que el dicho Gomes Manrrique o su lugarteniente a de estar con los alcaldes de la dicha çibdad en todos los casos çeviles e que sin el o sin su lugarteniente non puedan faser nin librar ninguna cosa, lo qual la dicha çibdad e los alcaldes de ella se fase grave e aun difiçile, e a el plase por su contenplaçion de non entender el nin otro por el en ellas nin en alguna de ellas, salvo si el rrey nuestro señor por nuebo mandamiento le mandase entender en algunas de las tales cosas çeviles que acaesçiesen, e que el mandamiento el non entendia procurar nin procuraria.

Yten, por quanto en las dicha provisiones asimesmo se contiene que el dicho Gomes Manrrique o su lugarteniente ayan de asistir con los dichos alcaldes en todas las causas criminales e que sin el o su lugarteniente non puedan entender en ellas los dichos alcaldes nin sea valedero lo que fisieren, e porque esto en alguna manera en los casos que podrian ocurryr que se fase grave, a el plase que se limite en esta guisa: que si los dias de carçel, que son lunes e miercoles e viernes, el dicho Gomes Manrrique o su lugarteniente non fueren a las abdiençias a las oras acostunbradas, que los dichos alcaldes o qualesquier de ellos puedan oyr e librar e que sea valedero lo que librasen; pero que en los otros casos que ocurrieren de crimen e pesquisa que se an de faser que lo ayan de noteficar al dicho 
Gomes Manrrique o a su lugarteniente, e que sin ellos o qualquier de ellos non puedan faser nin librar ninguna cosa salvo si el caso fuese tan esarruto que non sufriese esta dilaçion, que en tal caso puedan poner el rrecudio que entiendan que cunple e que aquel valga, pero a prosecuçion del negoçio que non se pueda proseguir sin el o sin su lugarteniente; pero si fecha la tal noteficaçion al dicho Gomes Manrrique o a su lugarteniente non pudieren yr a entender en el tal negoçio, que los dichos alcaldes o qualquier de ellos puedan porveer en el; e asimesmo que los dichos alcaldes o qualquier de ellos puedan rreçebir qualesquier denunçia que les sea dada e fecha sobre lo tal, rreçebir la ynformaçion que neçesaria sea, pero que en el proçeder despues de lo susodicho fecho que non se pueda faser sin el dicho Gomes Manrrique o su lugarteniente, segund que se ha de faser en la prosecuçion de las otras cabsas criminales.

Yten, por quanto en las dichas provisiones el rrey nuestro señor da poder al dicho Gomes Manrrique e a su lugarteniente para que pueda prender e soltar e desterrar a las personas que entendiere que cunple a su serviçio, lo qual en çierta forma a la dicha çibdad e a los alcaldes de ella se fase grave, a el plase que se modere en esta guisa: que quando el dicho Gomes Manrrique estoviera en la dicha çibdad, que el pueda prender $e$ mandar prender e soltar a los que asi prendiere non seyendo la cabsa muy grave; pero si la tal presion fuere sobre caso que se rrequiera coniçion del negoçio, que en tal coniçion es contento que entiendan con el o con su lugarteniente los alcaldes o qualesquier de ellos commo en las otras cosas criminales, e que non se suelte el tal preso salvo por mandamiento del dicho Gomes Manrrique o su lugarteniente e del alcalde o alcaldes que conoçieren la tal cabsa; e si los dichos alcaldes o alguno de ellos prendiere o mandare prender a alguna persona, asimesmo es contento de non lo mandar soltar si non juntamente con el alcalde que la tal presion oviere fecho o mandare faser; e asimesmo el dicho Gomes Manrrique plase de non desterrar a ninguna de las personas onrradas de la dicha çibdad sin lo consultar con los dichos alcaldes o con alguno de ellos; e asimesmo le plase que su lugarteniente en su absençia non pueda prender nin soltar nin desterrar a 99 ninguna persona sin los dichos alcaldes o alguno de ellos; pero en todo esto se entienda quedar a salvo si el rrey nuestro señor mandara por nueba provision prender o soltar a alguno, que en tal caso el o el dicho su lugarteniente lo puedan faser sin yr contra esta limitaçion..." ${ }^{175)}$.

Parece claro, pues, la distinta actuación que frente a los corregidores regios mostraron en todo momento las diferentes oligarquías de Cuenca y Burgos. En ello reside a mi juicio la clave para entender la también diferente "posibilidad" de acción de los monarcas con respecto a una u otra ciudad.

A la vista de todo lo dicho, creo poder afirmar que los éxitos alcanzados por los monarcas en el siglo XV en lo referente a la política de corregidores se basan no tanto en su estrategia como en la soterrada "ductilidad" de las oligarquías. En definitiva, la distinta composición y funcionamiento interno de las mismas, puede ser considerado un factor 
clave a la hora de analizar la mayor o menor "vulnerabilidad" de los concejos frente e los embates de la Corona. Frente a la resistencia que fueron capaces de oponer ciudades como Burgos, poseedoras de una fuerte conciencia oligárquica que alcanza su única y última justificación a través del control del sistema, Cuenca careció por entero de estas defensas. El carácter "noble" de la mayor parte de su oligarquía, bien por derecho de nacimiento, bien por encumbramiento desde orígenes más modestos, hace que prácticamente, ninguno de los miembros de dicha clase dirigente necesite del marco urbano para el mantenimiento de su estatus. El regimiento de Cuenca amplia el campo para el despliegue de sus influencias, pero no es imprescindible -a diferencia de Burgos- para el sostenimiento de su poder y dignidad. Pese a todo, en este contexto, se puede afirmar que, una vez consolidados los diferentes regímenes oligárquicos, toda la estrategia regia orientada a eliminar a la ciudad como resorte autónomo de poder, estaba destinada a convertirse en un éxito. Y la política de nombramiento de corregidores no iba a constituirse en ninguna excepción a esta regla. 


\section{NOTAS}

1. Sin olvidar los muchos trabajos realizados recientemente, cuya enumeración exhaustiva alargaría en exceso el presente trabajo, nos parece de especial significación al respecto citar el proyecto financiado por el Centro Nacional de Investigaciones Científicas que desde 1985 viene intentando aclarar los procesos que llevaron a la génesis del Estado Moderno en los reinos peninsulares de la Edad Media. Fruto de los trabajos ya realizados, dirigidos por la prof. Adeline Rucquoi, son dos recientes publicaciones que vienen a recoger de forma conjunta los hallazgos más recientes: Realidad e imágenes del poder. España a fines de la Edad Media. Adeline Rucqouoi (coord.). Valladolid, 1988 y Génesis medieval del Estado Moderno: Castilla y Navarra (1250-1370). Valladolid, 1987.

2. Al respecto, y al margen de los trabajos personales reseñados en la nota siguiente, sólo pueden citarse las dos importantísimas aportaciones del prof. Ladero: "El poder central y las ciudades en España del siglo XIV al final del Antiguo Régimen". Revista de Administración Pública, 1981, 173-198 y "Corona y ciudades en la Castilla del siglo XV". En la España Medieval. V. Estudios en memoria del prof. D. Claudio Sánchez-Albornoz. Vol. I.Madrid, 1986, 551-574.

3. Un primer esbozo de ello se contiene en el artículo "Burgos y Enrique IV. La importancia del sector ciudadano en la crisis castellana de la segunda mitad del siglo XV". Hispania, 1987. Asimismo, el tema se aborda especialmente en los siguientes trabajos: "Fórmulas de transmisión del poder en el sistema oligárquico burgalés del siglo XV". Actas del Congreso de Historia de Burgos. Valladolid, 1985; "Fiscalidad regia y poder municipal en Burgos (1453-1476)". En la España Medieval. V. Estudios en memoria del prof. D. Claudio SánchezAlbornoz. Madrid, 1986; "La Hermandad de 1476 en Burgos. Un factor decisivo en la transformación del poder municipal a fines de la Edad Media". Anuario de Estudios Medievales, Barcelona, 1986; conjuntamente con Jose $M^{\text {a }}$ Sánchez Benito, "La Corona y el poder municipal. Aproximación a su estudio a través de la elección a procuradores en Cortes en Cuenca y Burgos en el siglo XV". Las Cortes de Castilla y León. 1188-1988. Actas de la III etapa del Congreso Científico sobre la historia de las Cortes de Castilla y León. Vol. I. Valladolid, 1990 y "Del Concejo medieval a la ciudad moderna. El papel de las cartas expectativa de oficios ciudadanos en la transformación de los municipios castellanos bajomedievales: Burgos y Cuenca". // Congreso hispanoluso de historia medieval. Sevilla, noviembre de 1991 (en prensa).

4. M.A. Ladero Quesada, La Hacienda Real en Castilla en el siglo XV. La Laguna, 1973; del mismo autor, El siglo XV en Castilla. Fuentes de renta y política fiscal. Barcelona, 1982.

5. Y. Guerrero Navarrete, "Fiscalidad regia y poder municipal....

6. Y. Guerrero Navarrete, "La Hermandad de 1476 en Burgos.... 
7. M.A. Ladero Quesada, Castilla y la conquista del reino de Granada. Valladolid, 1967.

8. D. Menjot, "La ville et l'Etat moderne naissant: la monarchie et le Concejo de Murcie dans la Castille des Trastamares d'Henrì II à Henri IV". Realidad e imágenes del poder.....pp. 115.

9. A. Rucquoi "Pouvoir royal et oligarchies urbaines d'Alfonso $X$ à Fernando IV de Castille". Génesis medieval del Estado Moderno....pp. 211

10. Y. Guerrero Navarrete y J.M" . Sánchez Benito, "Del concejo medieval a la ciudad moderna...

11. H. Casado, "Las relaciones poder real-ciudades en Castilla en la primera mitad del sglo XIV". Génesis medieval....pp.211.

12. F. Albi, "El corregidor y la coadministración municipal". Revista de Estudios de la vida local, 1943, pp. 367.

13. A las clásicas obras de F. Albi (Vid. nota 12),A. Bermúdez Aznar, "El asistente real en los concejo castellanos bajomedievales". Actas del II Symposium de Historia de la Administración. Madrid, 1971, 223-252, y del mismo autor, El corregidor en Castilla durante la Baja Edad Media (1348-1474). Murcia,1974, B. González Alonso, El corregidor castellano (1348-1808). Madrid, 1970 y E. Mitre, La extensión del régimen de corregidores en el reinado de Enrique III de Castilla. Valladolid, 1969, hay que añadir la más reciente de A. Bermúdez Aznar, "Los concejos y la administración del reino". Concejos y ciudades en la Edad Media hispánica. II Congreso de Estudios Medievales. Madrid, 1990.

14. Vid. nota 3.

15. E. Mitre, La extensión del régimen de corregidores en el reinado de Enrique III de Castilla. Valladolid, 1969, pp. 18.

16. El artículo de E. Mitre citado anteriormente ya lo pone de manifiesto: $\mathrm{La}$ extensión del régimen de corregidores... pp. 62 y 63.

17. Según nuestras fuentes el reinado de Juan II registra el nombramiento de seis corregidores en Cuenca y uno en Burgos; Enrique IV designará cinco en Cuenca y tres en Burgos. Las diferencias son significativas si tenemos en cuenta que el reinado de Juan II cubre aproximadamente cincuenta años del siglo XV y el de Enrique IV sólo veinte. Además el porcentaje de actas municipales conservadas para el reinado de Juan II es muy superior a las del de su hijo.

18. A. Bermúdez Aznar, "Los concejos y la administración del reino". Concejos y ciudades en la Edad Media hispánica. II. Congreso de Estudios Medievales. Madrid, 1990, pp. 581.

19. "En un principio -afirma E. Mitre- se tendió a que el cargo fuera puramente temporal, y el nombramiento sólo se produjera en circunstancias excepcionales. A la larga se convertirá en algo permanente y, también, en el organismo casi exclusivo del gobierno municipal. Será el más eficaz agente de la política centralizadora de los monarcas..." (E. Mitre, op. cit. pp. 18). 
20. Font Rius resaltó en su día la consolidación de los sistemas de regimiento que restringían el gobierno urbano a la élite de poderosos y García de Valdeavellano menciona la recepción del derecho romano, entre otros (Cit. E. Mitre op. cit. pp. 16 y 17).

21. AMC, Leg, 187,3 , fols. $46 r-47 r$.

22. AMC, Leg.187,3,fols. 48r.

23. AMC., 194,4,fols. $51 \mathrm{v}$.

24. AMC,Leg, 194,4,fols. 33r-v.

25. AMC., Leg.194,4,fols. 36r.

26. AMB, LL.AA. 1411, fols. 8r-v.

27. Por motivo de la administración de los propios y rentas de la ciudad y, más concretamente, por una derrama de dinero efectuada entre los vecinos (Vid. nota anterior).

28. AMB. ,LL.AA. 1411, fols. $7 r-v$.

29. Ibid. fols. $8 \mathrm{v}$.

30. Ibid. fols. $15 \mathrm{r}$.

31. Ibid. fols. $34 v-35 r$.

32. AMB, LL.AA. 1463, fols. 113v-114r.

33. Y. Guerrero, "Burgos y Enrique IV. La importancia del sector......pp.

34. A.G.S., Sello, fol. 416 y 486.

35. Discursos históricos de la ciudad de Murcia, 1874, pp. 203.

36. Décadas. Lib. III, Cap. IV. Ed. BAC. Madrid, 1973, pp. 64.

37. E. Mitre, op. cit. pp. 54-61.

38. "Los concejos y la administración... pp. 573 y 576.

39. A modo de ejemplo, en 1428 se porduce en Cuenca un tímido y finalmente fracasado intento $d$ neutralización del nombramiento de corregidor bajo el pretexto de que la ciudad está en paz y no podría pagar el salario de un nuevo corregidor dado que el anterior, Gonzalo González de Madrid les dejó "sin dineros" (AMC,leg. 187,3, fols. 46r-47r).

40. En 1411, a Juan Sánchez de Ubeda, corregidor de Burgos se le deben mensualmente 3600 mrs. (AMB, LL.AA. 1411, fols. 33v, $45 v$ y $52 v$ ). En 1457 , el salario anual del corregidor monta un total de $18.000 \mathrm{mrs}$. por los días que estuvo presente en la ciudad y $10.200 \mathrm{mrs}$. por los que estuvo ausente en la Corte (AMC,leg.194,1, fols. 8 ryv). En 1458, al corregidor Fonseca le fue librado en Burgos por su salario $140.500 \mathrm{mrs}$. (AMB, LL.AA. 1458, fols. $4 \mathrm{v}-8 \mathrm{v}$ ). En 1459 , el corregidor Ulloa cobra en Cuenca un sueldo diario de $130 \mathrm{mrs}$., lo que hace un totl anual de $47.580 \mathrm{mrs}$. (AMC,leg.194,4, fols. 64 ryv). Y, por último, Rodrigo de Valderrábano cobra en Burgos en el año 1475800 mrs. diarios, 400 por su trabajo y 400 para el mantenimiento de gente armada, lo 
que sube un total de 288.000 mrs, anuales (AGS, Sello, fols. 418). Además, los corregidores solicitan otros pagos en ocasiones quecontribuyen a hacer aún más gravosa su estancia en la ciudad. En 1411, Juan Sánchez de Ubeda solicitó que le retribuyeran su participación en la obra de la barra de la puerta de Santa María de Burgos (AMB, LL.AA., 1411, fols. 52v.). En 1441 al corregidor conquense se le entregó, además del salario que le correspondía, colchones, sábanas, almohadas, dos armas talladas y otras cosas que la documentación no especifica (AMC,leg. 190,3,fols.16v). Por último, en 1459 Cuenca debe gastar $800 \mathrm{mrs}$. por el alquiler de unas casas de Sancho de Jaraba, pertenecientes a Alfonso de Alarcón, destinadas al corregidor (lbid. leg. 194,4, fols. 55r).

41. Por lo general, suelen hacer responsables del pago del salario del corregidor -si no en su totalidad, al menos en parte- a los habitantes de las villas o aldeas del señorío. Asi ocurre en Cuenca en 1455, 1459 y 1482 (AMC, leg. 193,2, fols. 31v-34v y 68v; leg. 194,4 fols. $87 \mathrm{r}-98 \mathrm{v}$ y 64 ryv; leg. 204,2, fols. 4r-7v) y en 1458 y 1461 en Burgos (AMB, LL.AA. 1458, fols. 121r-122r y LL.AA. 1461, fols. 97v-99v).

42. AMB, LL.AA. 1465, fols. 8r. Más adelante, una nueva insistencia sobre su recibimiento en fols. 20r.

43. AMC, leg. 194,1, fols. 1v.

44. Ibid. leg. 194,1 , fols. $7 v-8$ r.

45. Ibid. leg. 194,1, fols. 8 ryv.

46. Ibid. leg. 194,2 , fols. 14 ryv, $87 v-88$ r y 95 ryv; leg. 194,1 , fols. $28 r-30 v$, 36r$37 \mathrm{r}$ y $39 \mathrm{v}-40 \mathrm{v}$.

47. Ibid. leg. 194,2 , fols. 14 ryv y 54 ryv; leg. 194,3, fols. 5 ryv.

48. Ibid. leg. 194,2 , fols. 65 r; leg. 194,3 , fols. $10 \mathrm{v}$ y leg. 81,11 ; leg. 194,3 , fols. $19 \mathrm{v}$.

49. Ibid. leg. 194,2 , fols. $83 v$ y 84 r.

50. Ibid. leg. 194,3, fols. 25v-26v. Incluso todavía después de la sentencia, se incluye una mención a que Vergara ordenó asaltar a unos vecinos de Cuenca que iban a la feria de Villalón, tomándoles cerca de Olmedo ciertos paños y llevándoles a la torre "que llaman de la Ribera". Ante esto la ciudad decide enviar cartas de protesta al arzobispo de Sevilla y a Diego Arias.

51. Ibid. leg. 194,3, fols. 61v-62v.

52. AMC, leg. 834, 9.

53. AMC, leg. 189,1 , fols. $8 r-12 v$ y 189,2 , fols. $55 v$ y $65 v$.

54. AMC, leg. 204,2, fols. 32 ryv.

55. AMB, LL.AA. 1426, fols. 37v-40v, 42r-51v. J. Bonachía Hernando, El concejo de Burgos en la Baja Edad Media (1345-1426). Valladolid, 1978.

56. AMB, LL.AA $1445 / 46 / 47$, fols. $88 \mathrm{r}$ y $91 \mathrm{r}$ y LL.AA. 1450 , fols. $69 \mathrm{r}-70 \mathrm{v}, 74 \mathrm{v}-76 \mathrm{v}$, $79 \mathrm{v}, 80 \mathrm{r}, 85 \mathrm{r}, 98 \mathrm{r}$ y $105 \mathrm{v}$. 
57. AMB, LL.AA. 1431/32/33, fols. 65v-71r, 73r, 76v, 77r, 79r-81v, 86 ryv, 138 ryv, 143 ryv y $147 r$. LL.AA. 1463 , fols. $113 v-114 v$ y LL.AA. 1465 , fols. $8 r$ y $20 \mathrm{r}$.

58. AMB, LL.AA. 1427, fols. 80 ryv; LL.AA. 1429/30, fols. $21 v$, 79 ryv; LL.AA. 1431/32/33, fols. 4r; LL.AA. 1436, fols. 3v, 9 ryv, $10 \mathrm{v}$ y $11 \mathrm{r}$, 36v, 40r-41v.

59. Poseemos tres de estos documentos que mencionaremos a partir de ahora en varias ocasiones. Uno de Cuenca, data del año 1459, y hace referencia al recibimiento del corregidor Pedro de Ulloa en el que se dice textualmente que el corregidor deberá residir continuadamente en Cuenca durante el período de su mandato sin salir de ella, a menos que el concejo lo acepte (AMC, leg. 194,4, fols. 49 ryv y 51r). Las otras dos pertenecen a Burgos. La primera data de 1411, y en ella se impone a Juan Sánchez de Ubeda como cindición de su recibimiento que "no traspase el oficio" (AMB, LL.AA., 1411, fols. 15r). En la segunda, Gomez Manrique se ve obligado a aceptar lo siguiente: "Yten, por quanto el rrey nuestro señor manda yr al dicho Gomes Manrrique a la su corte, e la dicha çibdad ha por grave su absençia, a el plase que se tenga esta forma: que si el dia que partiere de la dicha çibdad en nobenta dias, asi agora como andando el tienpo, oviere de yr fuera de ella el por otros negoçios e non podiese bolber a la dicha çibdad, que el procurara en quanto podiere que en el tal caso la dicha çibdad soplique al rrey nuestro señor que le mande venir e le quite el negoçio de la dicha asistençia, a la qual suplicaçion el les çertifica de ayudar con todas sus fuerças e de non procurar que el rrey lo mande al contrario sin consentimiento de la dicha çibdad" (AMB, LL.AA. 1465, fols. 23 ryv).

60. En 1440, el rey da licencia a Gomez Días de Basurto, corregidor de Cuenca para ausentarse de la ciudad por 40 días, actuar durante este período a través de lugartenientes y, sin embargo, cobrar como si estuviese presente (AMC, leg. 190,3, fols. 15v-16r). En 1458, Enrique IV en vía a Burgos la siguiente misiva: "El rrey. Conçejo, alcaldes, meryno, rregidores, caballeros, escuderos, ofiçiales e omes buenos de la muy noble çibdad de Burgos, cabeça de Castilla mi camara, yo enbio mandar a Ferrando de Fonseca, my maestresala e my corregidor en esa çibdad, que por algunas cosas cunplideras a my serviçio venga aqui a my, en tanto que aca estoviere dexe alla sus ofiçiales para exerçer el dicho ofiçio, por ende yo vos mando que entretanto que aca estoviere le ayades por presente e le paguedes su salario e acudades con todos los derechos e cosas que le pertenesçieran, por manera que le non mengue cosa alguna, e myredes e acatades a sus ofiçiales que en los ofiçios dexare como a su persona mesma, e usedes con ellos en los ofiçios porque asy cunple a my serviçio, ca commo se aya despachado de lo que yo le mando faser, luego se bolvera a rresydir en el dicho ofiçio. E non fagades ende al. Fecho quinse dyas de março año de çinquenta e ocho. Yo el rrey. Por mandado del rrey, Alvar Gomes." (AMB, LL.AA., 1458, fols. 39r).

61. Ya no sólo lugartenientes, sino que, sobre todo en Cuenca, el corregidor como veremos después- tiene el derecho a nombrar ciertos oficiales, como al- 
caldes y alguacil, sirviéndose a veces de ellos como verdaderos lugartenientes de corregidor.

62. AMC, leg. 6, 20.

63. Incluso queda revocado el "alguacil de la tierra" y es designado uno nuevo por el corregidor (AMC, leg. 194,4, fols. 74v).

64. A modo de ejemplo a este respecto valgan los datos siguientes, incluidos en el Libro de Actas burgalés del año 1411. El 15 de julio, después de hablar de la relación que días atrás les hiciera Pedro García por orden de la reina, los oficiales del Regimiento de Burgos acuerdan hacer unas ordenanzas de justicia. Inmediatamente encargan al corregidor Juan Sánchez de Ubeda y al propio Pedro García su elaboración (AMB, LL.AA. 1411, fols. 36v). Seis días más tarde se ruega oficialmente a dicho corregidor que "use de su oficio" investigando y castigando a quienes han levantado rumores deshonrosos contra las dueñas de la ciudad, lo qual era en muy grand desonrra de la çibdad e vesinos della (Ibid. fols. 40r.). Finalmente, las ordenanzas fueron elaboradas, aprobadas por todos y juradas personal e individualmente (Ibid. fols. $40 \mathrm{v}-44 \mathrm{v}$ ).

65. En 1423 en Cuenca (AMC, leg. 187,2, fols. 26 ryv) o en 1464 en Burgos (AMB, S.H., $\mathrm{n}^{\circ}$ 2829).

66. AMC, leg. 187,2 , fols. 10 r y $26 \mathrm{v}$.

67. AMC, leg. 5, 91; leg. 5, 115 y 116; 6,10.

68. AMC, leg. 1108,3; 5, 114.

69. AMC, leg. 5,$98 ; 6,9$.

70. AMC, leg. 5, 96; 5, 99; 5, 101; 5, 117; 5,125. AGS, RGS, fols. 68 y fol. 202. AMB, S.H., no 3965 (bis), 1443, fols. 13v-14; 1089, fols. $29 \mathrm{v}-30 \mathrm{v}$; 4003 , fols. $19 \mathrm{v}$ 21v; 4003 (bis), fols. 8 y 9 y 12 y 13; 4221, fols. 8-9; Lib. Priv. fols. 310 ryv; 4046; AGS, RGS, fols. 460 y fols. 539 ; AMB, S.H., $n^{\circ} 3965,1089$ fols. $14 r-15 v$ y $n^{\circ}$ 4027.

71. Y. Guerrero Navarrete, J.M. Sánchez Benito, "Del concejo medieval a la ciudad moderna.....

72. AMC, leg. 187,2, fols. 1 ryv.

73. AMC, leg. 190,1 , fols. 35 ryv.

74. AMB, LL.AA. 1411, fols. 15v, 18r y $28 \mathrm{r}$.

75. AMB, LL.AA. 1465, fols. 22r-23v. 